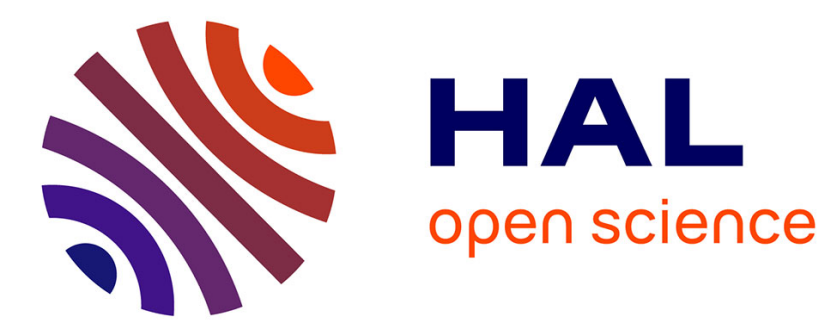

\title{
Development of Recrystallization Textures in Deep-Drawing Steels, Measured by X-Ray Diffraction and EBSD
}

\author{
M. Kiaei, B. Bacroix, J. Schmitt
}

\section{- To cite this version:}

M. Kiaei, B. Bacroix, J. Schmitt. Development of Recrystallization Textures in Deep-Drawing Steels, Measured by X-Ray Diffraction and EBSD. J. Phys. IV, 1995, 05 (C3), pp.C3-67-C3-75. 10.1051/jp4:1995306 . jpa-00253672

\section{HAL Id: jpa-00253672 https://hal.science/jpa-00253672}

Submitted on 1 Jan 1995

HAL is a multi-disciplinary open access archive for the deposit and dissemination of scientific research documents, whether they are published or not. The documents may come from teaching and research institutions in France or abroad, or from public or private research centers.
L'archive ouverte pluridisciplinaire HAL, est destinée au dépôt et à la diffusion de documents scientifiques de niveau recherche, publiés ou non, émanant des établissements d'enseignement et de recherche français ou étrangers, des laboratoires publics ou privés. 


\title{
Development of Recrystallization Textures in Deep-Drawing Steels, Measured by X-Ray Diffraction and EBSD
}

\author{
M. Kiaei*,**, B. Bacroix** and J.H. Schmitt* \\ *IRSID, Voie Romaine, B.P. 320, 57214 Maizière-lès-Metz cedex, France \\ ** LPMTM-CNRS, Université Paris Nord, Avenue J.B. Clément, Villetaneuse, France
}

\begin{abstract}
Résume
Le développement de textures de recristallisation a été étudié dans deux aciers à bas carbone destinés à l'emboutissage profond à l'aide de mesures globales de textures (par diffraction des rayons X) et locales d'orientations (par EBSD, Electron Back Scattering Diffraction ou diffraction des électrons rétro-diffusés). Les mesures globales permettent de caractériser de façon quantitative les textures de recristallisation et les mesures locales nous permettent de mettre en évidence une partie des mécanismes de germination et croissance qui sont à l'origine de ces textures. On montre ainsi que l'on a germination et croissance préférentielles des orientations de type $[111\}<u v w>$, parfois accompagnée de germination d'orientations aléatoires suivie d'une croissance limitée de celles-ci en présence de particules grossières de cémentite.
\end{abstract}

\begin{abstract}
The development of recrystallization textures in two low carbon steels used for deep drawing has been investigated through measurements of global textures (by X-Ray diffraction) and local orientations (by EBSD, Electron Back Scattering Diffraction). The global measurements allow a quantitative description of the recrystallization textures whereas the local measurements allow to identify some of the nucleation and growth mechanisms responsible for the development of the recrystallization textures. It is thus shown that preferred nucleation and growth of the $\{111\}<u v w>$ grains takes place in both steels, sometimes accompanied by nucleation of random orientations and limited growth of these grains, in the presence of coarse cementite particles.
\end{abstract}

\section{I/ Introduction}

In polycrystalline materials, texture changes during cold deformation and annealing are almost exclusively investigated through measurements of pole figures and the subsequent derivation of the orientation distribution function (ODF). This technique provides a quantitative information, although on a global scale: the main orientations of the final global texture - or macrotexture - are not correlated with the elements characterizing the microstructure, i.e. the size, shape and environment of individual grains. In particular, the fundamental mechanisms controlling the formation of recrystallization textures during annealing are not clearly identified by this technique. Two theories exist however in the literature to interpret the formation of annealing textures $(1)$ :

(i) the oriented nucleation theory assumes that special grains or grain boundaries act as preferential sites for nucleation, depending on their orientation: nucleation can occur through subgrain coalescence within grains with a high stored energy and high local misorientations between subgrains or through strain- 
induced boundary migration (SIBM) at grain boundaries between low stored energy grains and high stored energy grains, favouring the nucleation of low stored energy grains. In the case of cold-rolled low carbon steels, the first mechanism is believed to favour the nucleation of $\{111\}<u v w>$ grains (i.e. with a high stored encrgy), whereas the second would favour the nucleation of $\{100\}<u v w>$ grains (i.e. with a low stored energy).

(ii) the selected growth theory involves the rapid increase in size of nuclei characterized by particular misorientations with respect to the matrix. In the case of bec metals, a misorientation of $27^{\circ}$ around a $\langle 110\rangle$ axis is often invoked (2). In addition to this, it is also generally accepted that small angle boundaries are less mobile than large angle boundaries.

In order to get some information about the nucleation and growth rates of the orientations which will constitute the final recrystallization texture, it is thus necessary to correlate the macrotexture and the microstructure. This can be achieved by the EBSD technique (electron back scattering diffraction) which allows to determine locally the orientation of grains or subgrains within a given sample.

In this paper, global textures as well as the orientations of recrystallized grains have thus been measured in various steels at different steps of a continuous annealing treatment as well as those of the surrounding matrix: these measurements are expected to furnish some information about the nucleation mechanism(s) taking place in the investigated steels. As for the growth rate, it is believed that it is difficult to characterize it in polycrystalline materials, since the environment of a growing grain changes each time a new grain is reached by the moving boundary. Misorientations between recrystallized and non recrystallized grains will nevertheless be calculated from some of the individual orientation measurements.

\section{II/ Experimental procedure}

The investigated materials are an interstitial frce steel (Ti-IF) and an aluminium killed steel (Al-K) containing $0.001 \% \mathrm{C}$ and $0.055 \% \mathrm{Ti}$ for the first and $0.027 \% \mathrm{C}$ for the second (in weight percent). These steels were first cold rolled industrially to a final rolling reduction of $70 \%$ and a final thickness of $0.7 \mathrm{~mm}$. Laboratory simulations of continuous annealing were then carried out: each specimen was heated up to various temperatures to the "full recrystallization" temperature at a heating rate of $10 \mathrm{deg} / \mathrm{s}$ and then waterquenched without holding. The full recrystallization temperature, which is the temperature at which this continuous annealing treatment leads to complete recrystallization of the specimen, was determined by Vickers hardness measurements.

Samples for global texture measurements were prepared from the mid-thickness of the rolled and annealed specimens by cutting, mechanical polishing and electropolishing. Local textures were carried out on transversal sections (i.e. perpendicular to the transverse direction of the sheet) in the middle of the thickness of the sheets.

The orientations of the recrystallized grains and of the deformed grains of the surrounding matrix were determined by EBSD in a scanning electron microscope. The two kinds of grains, i.e. in a recrystallized or deformed state (but slightly recovered), were easily distinguished by the quality of EBSD patterns which are stable and clear for the recrystallized grains and blurred for the matrix ones. A total of about 300 orientations of recrystallized grains and 150 orientations of matrix deformed grains were measured for each specimen.

\section{III/ Results}

\section{III/1. Global textures}

\section{a/ Aluminium killed steel (AI-K)}

The variation of the ODF along the so-called $\alpha(R D / /<110>)$ and $\gamma(N D / /<111>)$ fibres which contain most of the orientations constituting the texture of both rolled and annealed sheets is shown in Figure 1 ,

The texture of the hot band (not shown here) is very weak. Cold rolling leads then to a strong texture, typical of this deformation path: the $\gamma$ fibre is more or less uniform and the highest intensity on the $\alpha$ fibre 
is located in the vicinity of the $\{112\}<110>$ orientation followed by two secondary peaks on the $\{111\}<110>$ and $\{001\}<110>$ orientations.

As the annealing temperature is incrcased, the intensity of the $\alpha$ fibre first increases in the range $\Phi=0$ to $30^{\circ}$ and then decreases drastically above $634^{\circ} \mathrm{C}$. Along the $\gamma$ fibre, the value of the ODF first coincide more or less with that of the cold-rolled state and above $634^{\circ} \mathrm{C}$, the intensity of the $\{111\}<112>$ orientation decreases and that of the $\{111\}<110>$ orientation remains constant. The measured recrystallized fractions at 618,634 and $716^{\circ} \mathrm{C}$ are equal to 5,20 and $100 \%$ respectively.
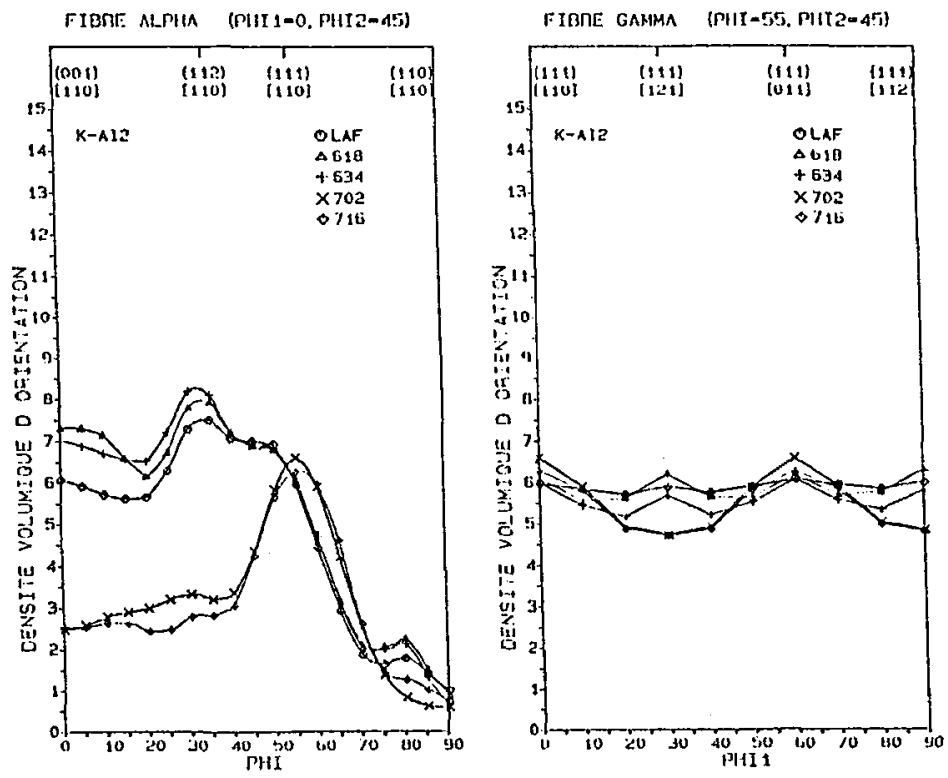

Figure 1: Global textures along the $\alpha$ and $\gamma$ fibres for the Al-K steel ( $\mathrm{LAC}=$ hot rolling and $\mathrm{LAF}=$ cold rolling).

\section{b/ Interstitial free steel (Ti-IF)}

The intensities along the $\alpha$ and $\gamma$ fibres measured after hot and cold rolling and various annealing temperatures are shown in Figure 2. The texture of the hot band is again rather weak. The cold rolling texture is stronger than in the Al-K steel but the $\gamma$ fibre is less uniform; the $\{111\}<110>$ components are stronger than the $\{111\}<112>$ components. The $\alpha$ fibre contains a major and wide peak in the vicinity of $\{223\}<110>$, followed by a secondary peak at the $\{001\}<110>$ orientation.

As the annealing temperature is increased, the wide peak on the $\alpha$ fibre is first divided into two peaks located in the vicinity of the $(112)<110>$ and $(111)<110>$ orientations. Simultaneously, the intensity of the $\alpha$ fibre increases slightly in the range $\Phi=0$ to $30^{\circ}$. The intensity of the $\gamma$ fibre is constant until $692^{\circ} \mathrm{C}$. At $754^{\circ} \mathrm{C}$, the intensity of the $\{111\}<112>$ orientation decreases whereas that of the $\{111\}<110>$ orientation is increased. At higher temperatures, the intensity of the whole fibre increases. At the same time, the $\{100\}$ peak decreases drastically on the $\alpha$ fibre.

The recrystallized fractions have been measured at 734,740 and $798^{\circ} \mathrm{C}$, where they are equal to 25,60 and $100 \%$ respectively.

For both steels, the development of the annealing texture can be summarized as follows: the uniformity along the $\gamma$ fibre, if present before annealing, is lost, the $\{111\}<110>$ component becoming the strongest component and the intensity of the $\{001\}<110>$ component first slightly increases and then strongly decreases. Furthermore, the overall intensity of the global texture increases during recrystallization for the 
Ti-IF steel. It is worth mentioning that, in both steels, a quantitative change is clearly visible on these measurements only when the recrystallized fraction is sufficiently high (above 20\%), i.e. only when the recrystallization process is well advanced. It is thus difficult to characterize the beginning of recrystallization from these measurements.
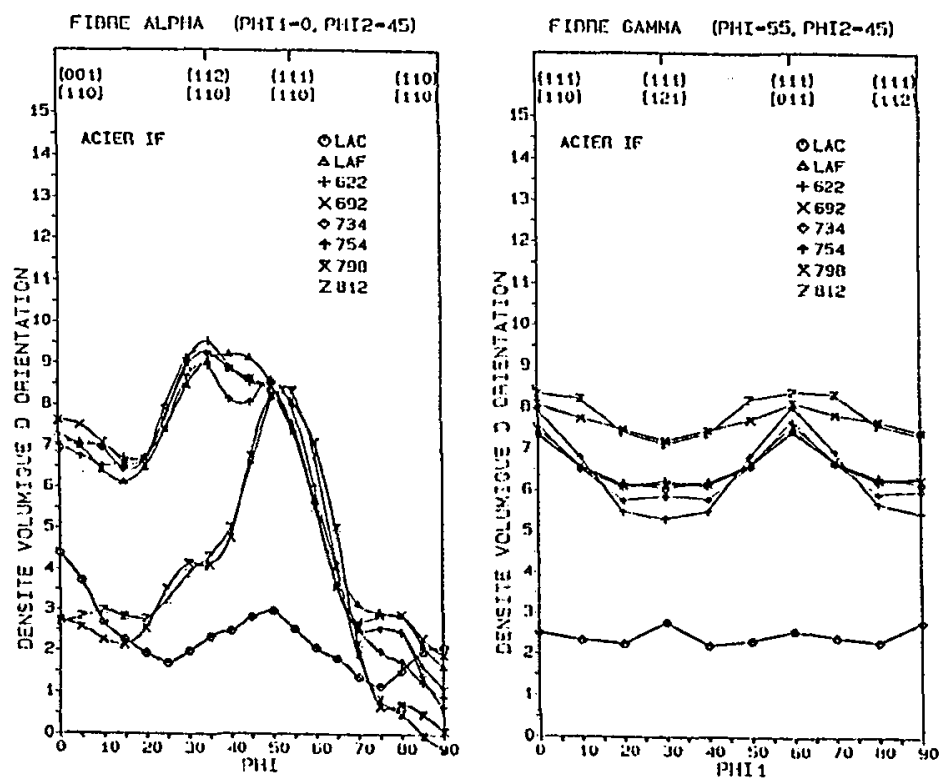

Figure 2: Global textures along the $\alpha$ and $\gamma$ fibres for the Ti-IF steel

\section{III/2. Local textures}

\section{a/ Aluminium killed steel (Al-K)}

Local texture measurements were carried out at the temperatures of 618,634 and $718^{\circ} \mathrm{C}$ at which the recrystallized fractions are 5,20 and $100 \%$ respectively (Figure $3 \mathbf{a}$ ).

At $618^{\circ} \mathrm{C}$, the first recrystallized grains are represented by a majority of $\{111\}<u v w>$ orientations (with a maximum of $\{111\}<110>$ grains) followed by $\alpha$ components in the range $\Phi=0$ to $30^{\circ}$. This texture is roughly the same than the local texture of the deformed matrix (Figure $3 \mathrm{~b}$ ). At $634^{\circ} \mathrm{C}$, the results are very similar to those described above, although the scatter is slightly more important for the orientation of the normal direction in the recrystallized grains and the orientations within the deformed matrix are more concentrated on the $\alpha$ fibre. After complete recrystallization (at $718^{\circ} \mathrm{C}$ ), there is still a major concentration of orientations around $<111>/ / \mathrm{ND}$ but the orientation scattering increases. It seems to be even more important than expected from the previous ODF representations (Figure 1). 

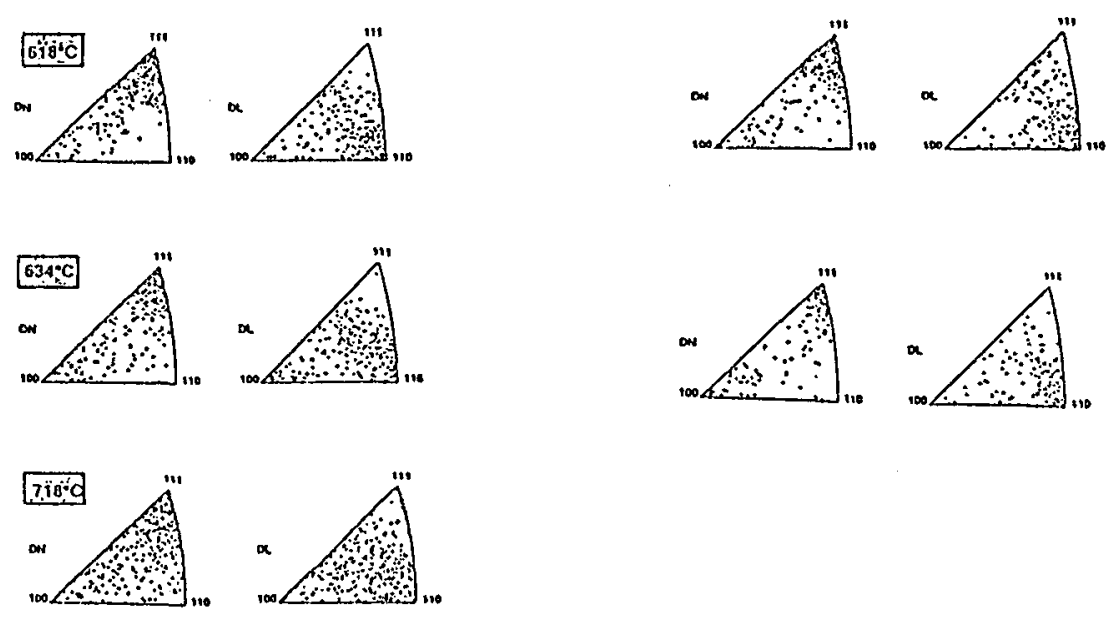

Figure 3: Local measurements in Al-K steel

$a /$ the recrystallized grains and $b /$ the deformed matrix grains

$(\mathrm{DN}=$ normal direction and $\mathrm{DL}=$ rolling dircetion $)$.

\section{b/ Interstitial free steel (Ti-IF)}

Local texture measurements were carried out at the temperatures of 734,740 and $798^{\circ} \mathrm{C}$ at which the recrystallized fractions are 25,60 and 100\% respectively (Figures $4 \mathrm{a}$ and $4 \mathrm{~b}$ ). In this first series of measurements, the beginning of the recrystallization process was not studied for this steel but will be presented in a forthcoming paper. As expected from the ODF measurements, the scatter of orientations is less in this stecl than in the previous one.

At $734^{\circ} \mathrm{C}$, the orientations of the recrystallized grains are located on both $\alpha$ and $\gamma$ fibres (Figure 4a) whereas the orientations of the matrix grains are essentially located on the $\alpha$ fibre (Figure $4 \mathrm{~b}$ ). As the annealing temperature is increased, the scatter of orientations within the recrystallized grains decreases and tend towards a strong $\gamma$ fibre. When the recrystallized fraction is equal to $60 \%$, the orientations of the matrix grains are again exclusively concentrated on the $\alpha$ fibre. 

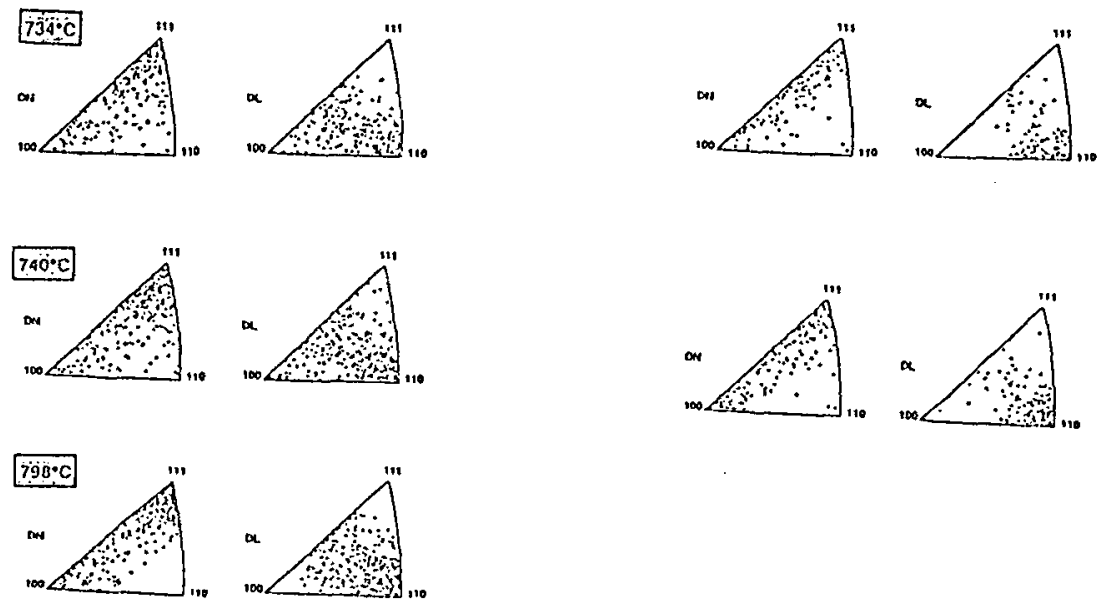

Figure 4: Local measurements in the Ti-IF steel a/ the recrystallized grains and $b /$ the deformed matrix grains (DN = normal direction and $\mathrm{DL}=$ rolling direction).

\section{III/3. Orientation relationships}

As the present experimental data concern mainly the nucleation mechanisms (and thus the very beginning of the growth process), the misorientations between the recrystallized grains and the surrounding matrix will be presented only for the Al-K steel at the beginning of recrystallization (i.e. for the anncaling treatment realized at $618^{\circ} \mathrm{C}$ ). These are shown in Figures 5 and 6 : the smatl misorientation angles (less than $10^{\circ}$ ) as well as the large misorientation angles (greiter than $50^{\circ}$ ) are significantly more numerous in the present case than in an isotropic sample in the absence of specific orientation correlations (3). In the latter case, the most frequent misorientation is found around $40^{\circ}$. The small misoriention angles may be related to the nucleation process whereas the large misorientation angles are most probably associated with the rolling symmetry: the symmetrical $\{111\}<110>$ and $\{111\}<112>$ orientations are related by a $60^{\circ}<111>$ misorientation. A preferred $27^{\circ}$ misorientation around a $<110>$ axis maly also be seen on these figures but the number of measurements is too limited to be conclusive.
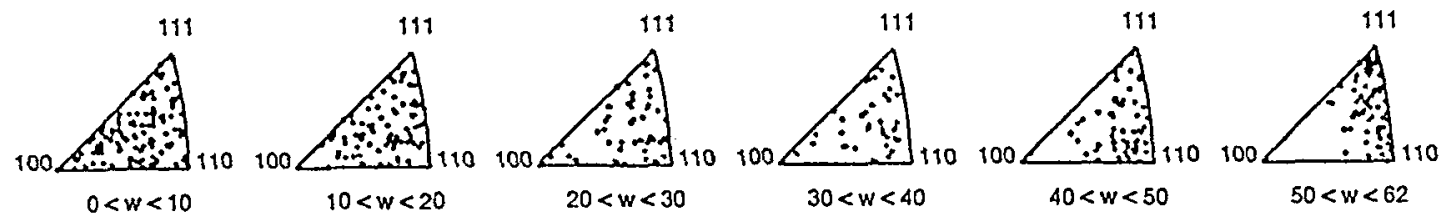

Figure 5: Axes and angles of misorientations bewteen the recrystallized grains and the surrounding matrix in the $\mathrm{Al}-\mathrm{K}$ steel at $618^{\circ} \mathrm{C}$. 


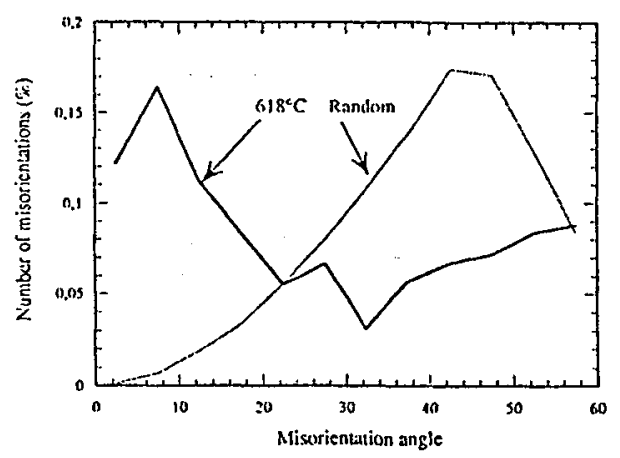

Figure 6: Number of misorientation angles counted in the $\mathrm{Al-K}$ steel at $618^{\circ} \mathrm{C}$ (from Figure 5 ).

\section{IV/ Discussion}

It may be first of interest to compare the global and local texture measurements (Figures 1 to 4 ): the first one includes both recrystallized and non recrystallized grains and is quantitative whereas the second one allows to distinguish between the two types of grains and, as represented in the present work, is essentially qualitative. Nevertheless, these two types of measurements are coherent (compare Figures 1,2 and Figures $3+4$ ), although the EBSD textures seem to be more scattered than the global textures. Both $\alpha$ and $\gamma$ fibres are clearly present in the EBSD measurements, which means that these are representative of the textures of the investigated materials. A quantitative comparison of both types of measurements can then be realized by calculating ODFs from the single orientation measurements. This will be done in future work and will allow to evaluate quantitatively the orientation scatter already mentioned above, which is visible in Figure 2 in the case of the Al-K steel.

Now concerning the nucleation mechanisms, the present data indicate that nucleation of high stored energy grains (i.e. the (111) grains) occurs in both steels, maybe through subgrain coalescence. This last point will have to be checked locally, by examination of the microstructure and local determination of the spread of orientations within the [111] grains. Nevertheless, the occurrence of this mechanism is coherent with the fact that the orientations of the first recrystallized grains are very close to the ones of the surrounding deformed grains or subgrains (see Figures 3 and 4). The present results are also coherent with the ones already reported by other authors in Ti-IF steels $(4,5)$.

Apart from this mechanism, strain induced boundary migration (SIBM) could be responsible for the small increase of the $(001)<110>$ orientation which occurs in the first steps of recrystallization: such an increase has also been reported by Emren et al. (6) in the case of different types of steels isothermally annealed at $700^{\circ} \mathrm{C}$ for various holding times, and was also attributed by these authors to SIBM. In the present work, the increase of the $\{100\}$ component is especially visible in the Al-K steel (Figure 1) in which the subgrain coalescence mechanism may be impeded by the presence of coarse cementite particles (see below). It is worth noting that the increase of the $\{001\}<110>$ component is not obvious from the EBSD measurements, where it is seen that $\{100\}$ grains are present in both steels, in both recrystallized and deformed grains and at all stages of the recrystallization process: the occurrence of SIBM will also have to be checked by a quantitative analysis of the EBSD data.

The presence of coarse particles in the Al-K steel could also be responsible for the differences observed in both deformation and recrystallization textures for the two types of stecls. In the Al-K steel, since the coiling temperature is high, solute elements like nitrogen are completely precipitated before cold rolling and cementite particles are coarse. The effect of such coarse cementite particles on the development of recrystallization textures in high purity iron have already been investigated by Inagaki $(7,8)$. Texture and microstructure development during deformation and recrystallization have been studied metallographically 
in an $\mathrm{Fe}-0.02 \% \mathrm{C}$ alloy containing coarse cementite particles. It has been found that these particles, which are precipitated initially on grain boundaries are fragmented during cold rolling into rows of smaller particles. These fragmented particles further rotate and arrange themselves into more stable configurations. Through this process, deformed zones, in which local strains are accumulated, are developed around each particle. During annealing, nucleation occurs most readily in these deformed zones in which the dislocation density is high. Due to the complex deformation which occurs around each particle during rolling, orientation distributions within the deformed zone are more or less random, which leads in turn to a random nucleation process during the first steps of the recrystallization process. The presence of these particles would thus lead to a weakening of both deformation textures (due to the presence of highly deformed zones in an heterogeneous manner) and recrystallization textures (due to random nucleation in these zones), as observed in the present case. Inagaki has also shown that this effect of the coarse cementite particles was more prominent at lower annealing temperatures. At later stages of the recrystallization process or at higher annealing temperatures, nucleation may occur also at other nucleation sites than the fragmented particles.

Thus, three nucleation mechanisms may occur in Al-K steels: subgrain coalescence leading to nuclention of (111) grains, SIBM leading to an increase of the $\{001\}<110\rangle$ component (in the first stages of recrystallization only) and random nucleation within deformed zones around the coarse cementite particles, which tends to weaken the texture intensity. These three nucleation processes seem to be followed by a homogeneous growth mechanism, which may also be limited by the presence of particles.

In Ti-IF steels, the present results may be mostly interpreted in terms of subgrain coalescence in the (111) grains followed by a selected growth process as reported previously $(4,5)$; the growth process invoked by these authors is the following: $(111\}<110>$ recrystallized grains nucleate first within $\{111\}<110>$ deformation grains which are close to $\{111\}<112>$ deformed grains and grow at the expense of these last grains. The orientation relationship between the $(111\}<110>$ and $\{111\}<112>$ orientations is a totation of $30^{\circ}$ around a $<111>$ axis which corresponds to a $\Sigma(7)$ coincidence site. This first nucleation and growth step leads to a decrease of the $(111)<112>$ component (see Figure 1b). Then, as there is no more favourable environment for the nucleation of $\{111\}<110>$ orientations close to grain boundaries separating $\{111\}<110>$ and $\{111\}<112>$ deformed grains, $\{111\}<112>$ recrystallized grains nucleate within $(111)<112>$ deformed grains, close to $\{110\}<112>$ deformed grains and grow again at the expense of these last grains. The orientation relationship between $(111\}<112>$ and $(110)<112>$ orientations is described as a rotation of $35^{\circ}$ around a $<110>$ axis, which is not very far from the $27^{\circ}$ rotation around a $<110>$ axis which corresponds to the $\Sigma(19 \mathrm{a})$ coincidence site, and is often associated with a fast growing rate $(2,9)$. This second nucleation and growth step leads to a decrease of the $\{110\}<112>$ orientation (Figure 1b). This scenario, which is in partial agreement with the global textures reported in the present work (it does not explain the disappearance of the $\{001\}<110>$ component), will also have to be verified locally by inspection of the environment of the recrystallized $(111)<110\rangle$ and $(111)<112\rangle$ grains at the very beginning of recrystallization.

\section{V/ Conclusions and perspectives}

The development of recrystallization textures have been investigated in two ultra low carbon steels by means of global and local textures measurements. In both cases, the hot rolling texture is weak and the cold rolling texture can be described by the two $\alpha$ and $\gamma$ fibres: the $\alpha$ fibre present a maximum close to the $\{111\}<110>$ orientation followed by a secondary peak on the $\{001\}<110>$ component; the $\gamma$ fibre is uniform in the Al-K stcel but presents a maximum in the vicinity of the $\{111\}<110>$ orientation in the Ti-IF steel.

Recrystallization leads then to a small increase followed by a strong decrease of the $\{001\}<110>$ component and the evolution along the $\gamma$ fibre depends upon the type of steels: in both cases, the main component is the $(111)<110>$ orientation and the minimum intensity is located on the $\{111\}<112>$ orientation but the average intensity of the fibre is constant in the AI-K steel and increases in the Ti-IF steel. Both deformation and recrystallization textures are weaker in the Al-K steel than in the Ti-IF steel.

EBSD measurements indicate that there is preferential nucleation of $\{111\}$ grains in both steels, accompanied by some random nucleation in the Al-K steel.

These global and local textures may be interpreted as follows: 
- In the Al-K steel, three different nucleation processes take place, which are (i) the coalescence of (111) subgrains, (ii) some strain induced boundary migration leading to an increase of the $\{100\}$ component and (iii) some nucleation of random orientations close to the coarse cementite particles. Growth of these various orientations is then limited by the presence of the particles.

- In the Ti-IF steel, preferred coalescence of (111\} grains takes place, which may be followed by a selected growth mechanism.

This interpretation will have to be verified experimentally by:

- a quantitative analysis of the EBSD data; this will allow to determine the location of the $\{100\}$ grains and verify or contradict the hypothesis of SIBM;

- a local examination of the environment of some growing grains, in various sections of the samples in order to provide some information about the misorientations really present in the material; this will have to bc done at the very beginning of the recrystallization process where the selectivity of the growth rate is believed to play a major role in polycrystalline materials;

- the study of the very beginning of recrystallization in the Ti-IF steel, which is missing in the present paper.

\section{References}

1/ D. Vanderschueren, P. Van Iloutte, E. Aernoudt, J. Dilewijns and C. Standaert, in Advances in Hot Deformation Textures and Microstructures, J.J. Jonas, T.R. Bieler and K.J.Bowman eds, TMS, 1994, p. 95.

2/ G. Ibe, K. Lücke, Arch. Eisenhütenwes, 29, 1968, p. 693.

3/ A. Garbacz and M.W. Grabski, Acta metall. mater, 41, 1993, p. 469.

4/ W.B. Hutchinson, Acta metall., 37, 1989, p. 1047.

5/ II. Inagaki, Trans. ISIJ, 24, 1984, p. 266.

6/ F. Emren, U.Von Schlippenbach, K. Lücke, Acta Metall., 34, 1986, p. 2105.

$7 /$ H. Inagaki, Z. Metallkde., 82, 1991, p. 99.

8/ H. Inagaki, Z. Metallkde., 78, 1987, p. 630.

9/ D. Raabe, K. Lücke, Scrip. Metall. et Mater., 27, 1992, p. 1533. 